\title{
Mental Health Interventions Provided by Volunteer Psychiatrists after the Sewol Ferry Disaster: April 16-November 30, 2014
}

\author{
Seung Min $\mathrm{Bae}^{1 *}$, Mi-Sun Lee ${ }^{2 \star}$, Eunji Kim ${ }^{3}$, Jiyoun Kim${ }^{4}$, Juhyun Lee ${ }^{5}$, Jun-Won Hwang ${ }^{6}$, \\ Hyoung Yoon Chang ${ }^{7,8}$, Cheol-Soon Lee ${ }^{9}$, Jangho Park ${ }^{10}$, and Soo-Young Bhang ${ }^{11}$ \\ 1'Department of Psychiatry, Gachon University School of Medicine, Gil Medical Center, Incheon, Republic of Korea \\ ${ }^{2}$ Department of Meditation Psychology, Nungin University, Hwaseong, Republic of Korea \\ ${ }^{3}$ Maumtodak Psychiatry Clinic, Ansan, Republic of Korea \\ ${ }^{4}$ Goodmind Psychiatry Clinic, Suwon, Republic of Korea \\ ${ }^{5}$ Inarae Psychiatry Clinic, Seoul, Republic of Korea \\ ${ }^{6}$ Department of Psychiatry, Kangwon National University School of Medicine, Chuncheon, Republic of Korea \\ ${ }^{7}$ Department of Psychiatry, Ajou University School of Medicine, Suwon, Republic of Korea \\ ${ }^{8}$ Sunflower Center of Southern Gyeonggi for Women and Children Victims of Violence, Suwon, Republic of Korea \\ ${ }^{9}$ Department of Psychiatry, Gyeongsang National University School of Medicine, Gyeongsang National University Changwon Hospital, Changwon, \\ Republic of Korea \\ ${ }^{10}$ Department of Psychiatry, University of Ulsan College of Medicine, Ulsan University Hospital, Ulsan, Republic of Korea \\ ${ }^{11}$ Department of Psychiatry, Eulji University School of Medicine, Eulji University Hospital, Seoul, Republic of Korea
}

Objective The aim of this study was to examine the experience of volunteer psychiatrists who provided mental health interventions to adolescents and teachers of Danwon High School from April 16, 2014, to November 30, 2014.

Methods Data for this study were collected from 72 volunteer psychiatrists about their intervention experiences for 212 adolescents and 32 teachers during the eight months following the disaster. Developmental survey themes were identified, and coding was used to analyze the data. In addition, qualitative data analysis was performed using ATLAS.ti (version 8.2, 2018, ATLAS.ti GmbH).

Results A volunteer prepared with appropriate mental health interventions may facilitate the emergency response to a disaster. Intervention services included psychological first aid, psychoeducation, screening, anxiety reduction techniques, and group therapy.

Conclusion In the acute aftermath of the Sewol Ferry disaster of April 16, 2014, volunteer psychiatrists were able to provide mental health interventions in a disaster response setting. The outcomes from this study have important policy and mental health system implications for volunteer psychiatrists. The results of this study constitute the basis of a better understanding of the essential mechanisms of crisis interventions after a disaster.

Psychiatry Investig 2019;16(7):513-523

Key Words Volunteer psychiatrist, Disaster psychiatry, Mental health intervention, Trauma, Sewol Ferry disaster.

\section{INTRODUCTION}

Psychiatrists have a key role, such as caring for the victims and the overall community, in a disaster response. ${ }^{1}$ And their activity in disaster is one of the very important factors for re-

\footnotetext{
Received: December 26, 2018 Revised: February 12, 2019 Accepted: April 30, 2019

$\triangle$ Correspondence: Soo-Young Bhang, MD, MPH, PhD

Department of Psychiatry, Eulji University School of Medicine, Eulji University Hospital, 68 Hangeulbiseok-ro, Nowon-gu, Seoul 01830, Republic of Korea Tel: +82-2-970-8303, Fax: +82-2-970-8429, E-mail: dresme@dreamwiz.com

*These authors contributed equally to this work.

(c) This is an Open Access article distributed under the terms of the Creative Commons Attribution Non-Commercial License (https://creativecommons.org/licenses/by$\mathrm{nc} / 4.0$ ) which permits unrestricted non-commercial use, distribution, and reproduction in any medium, provided the original work is properly cited.
}

covery. ${ }^{2-4}$ Volunteer psychiatrists could access mental health problems of survivors of disaster exposure and suggest appropriate interventions shortly after the disaster. ${ }^{1}$ After Hurricane Katrina, it showed that the volunteer psychiatrists provided the mental health services and conducted a distinct role of intervening for evacuees. ${ }^{5}$

In South Korea, on April 16, 2014, most of the victims in the Sewol Ferry disaster were children and adolescents and included students attending Danwon High School. ${ }^{6}$ At that time, psychological support was urgently provided for the students of Danwon High School who were survivors of the Sewol Ferry disaster. The government had established a crisis response system in cooperation with the medical staff of the Korean Neuropsychiatric Association and the Korean Academy of 
Child and Adolescent Psychiatry. Additionally, training for the disaster crisis intervention was conducted for volunteer psychiatrists. Volunteer psychiatrists who had completed disaster crisis intervention training provided students with systematic and professional psychological support so that students could return to school and achieve stabilization and normalization.

Nevertheless, no previous study has been reported on the experiences of and progress made by volunteer psychiatrists in actual disaster situations. Additionally, information regarding the interventions in the Sewol Ferry disaster has been limited, depending on the situation. Nevertheless, it is important to obtain information from experienced volunteer psychiatrists on mental health assessment and intervention for children and adolescents exposed to disaster. Through this information, volunteer psychiatrists could provide the necessary intervention to the victims exposed to the disaster, and guide them on additional recommendations. ${ }^{2}$ Therefore, it is urgent to establish the evidence for intervention in mental health services for children, adolescents, teachers, and parents following major domestic disasters.

Based on this, we conducted an empirical study on psychiatrists who participated as volunteers after the Sewol Ferry disaster, to understand the psychosocial intervention methods. In addition, we intended to identify effective psychological crisis intervention and evaluation plans in case of domestic disaster in the future.

\section{METHODS}

\section{Participants}

The participants were psychiatrists of the Korean Neuropsychiatric Association or Korean Academy of Child and Adolescent Psychiatry who experienced volunteering for disaster victims after the Sewol Ferry disaster. The psychiatrists were excluded if the volunteers were not able to provide enough professional information or did not agree to participate in the study. The questionnaire was sent to a total of 159 psychiatrists, who were volunteers at the time of the disaster, and the purpose of the study was explained individually through email, mail, and face-to-face contact. We provided information, including the main title of the research project and the contents of the questionnaires, and a guarantee of anonymity to the participants, and we conducted the research only after they agreed to participate. The study was approved by Eulji University's Institutional Review Board (IRB No. EMCS 201602-004).

\section{Questionnaire}

The questionnaire items were developed by referring to a previous study ${ }^{2}$ on the volunteer experience of psychiatrists. We collected opinions from five mental health professionals who had experience with the treatment of children and adolescents exposed to the disaster. Afterwards, the items of each element were supplemented and structured. Finally, creation of the questionnaire was completed by revising the items. The questionnaire consisted of 57 items, including items related to demographic characteristics ( 8 items), the motivation of the volunteer (4), the time frame of volunteering (4), training as a volunteer (3), individual interviews with students (12), participation in group sessions (7), participation in small group sessions (8), teacher interviews (5), satisfaction with volunteering (2), and willingness to participate as a volunteer in the future (4). The questionnaire consisted of multiple choice and open-ended questions The questionnaire was self-administered by the participants (Table 1).

\section{Process}

The final questionnaire was distributed from April 4, 2016 to May 17, 2016, and the data were collected via e-mail, mail, or in person. The return envelope was sent after the questionnaire was delivered with a return postage stamp, and the email was sent with the questionnaire file attached. To increase the recovery rate, we sent out the questionnaires and return envelopes and the e-mails more than 3 times. We collected the completed questionnaires through each method. For the final analysis, we received questionnaires from 72 respondents by July 8,2016 , resulting in a recovery rate of $45.28 \%$.

\section{Statistical analysis}

The collected questionnaires were coded by the researcher, entered into a computer, and processed based on the purpose of the data analysis. We assessed the suitability of responses to each question. In the case of open responses, we performed a classification through content analysis. To investigate the demographic characteristics and volunteer experience of the participants, quantitative analysis (frequency and percentage) was conducted using the IBM SPSS Statistics 20.0 program (IBM Corp., Armonk, NY, USA). Qualitative data analytic techniques were applied to the opinions and suggestions from respondents using ATLAS.ti software version 8.2 (Scientific Software Development GmbH, Germany).?

\section{RESULTS}

\section{The demographic characteristics of the participants}

A total of 72 psychiatrists (mean age: 43.67 years \pm 8.25 ) responded to the final questionnaire. Fifty-one $(70.8 \%)$ of the volunteer psychiatrists were female. Thirty-six (50.0\%) had a doctoral degree, 25 (34.7\%) had a master's degree, and 11 
Table 1. Categories and items included in the interview of the volunteer psychiatrists

\begin{tabular}{|c|c|}
\hline Categories & Items \\
\hline \multirow[t]{4}{*}{ I. Motivation for volunteering } & 1) Motivation for participation as a volunteer \\
\hline & 2) How to apply for volunteers \\
\hline & 3) Experience as a volunteer \\
\hline & 4) Previous experience with volunteering as a disaster volunteer \\
\hline \multirow[t]{4}{*}{ II. Time dedicated to volunteering } & 1) Average travel time to volunteer site \\
\hline & 2) Total number of visits to the disaster site \\
\hline & 3) Starting and end date of volunteering \\
\hline & 4) Total duration of volunteer work \\
\hline \multirow[t]{3}{*}{ III. Volunteer training } & 1) Training programs for volunteers \\
\hline & 2) Details of the training program \\
\hline & 3) Total education time for volunteers \\
\hline \multirow[t]{12}{*}{ IV. Individual interviews with the students } & 1) Number of interviewed students \\
\hline & 2) Average interview time per session \\
\hline & 3) Total interview time each visit \\
\hline & 4) The time frame of the individual interviews with students after the disaster \\
\hline & 5) The degree of memory for the interviewed student \\
\hline & 6) Total number of sessions per student \\
\hline & 7) Results of student interview \\
\hline & 8) Number of absent students \\
\hline & 9) Reasons for student's absence \\
\hline & 10) Attitudes of students during individual interviews \\
\hline & 11) The degree of change in students after interview \\
\hline & 12) Recommendations for action after student interview \\
\hline \multirow[t]{7}{*}{ V. Participation in group sessions } & 1) Participation in group session (classroom) \\
\hline & 2) Total number of sessions participating in the group program \\
\hline & 3) The time frame of group sessions after the disaster \\
\hline & 4) Main contents of each session program \\
\hline & 5) Students' responses in group session \\
\hline & 6) Effectiveness of group session \\
\hline & 7) Supplementary points and additions to group session \\
\hline \multirow[t]{8}{*}{ VI. Participation in small group sessions } & 1) Participation in small group session \\
\hline & 2) Location of small group session \\
\hline & 3) Total number of sessions participating in the small group program \\
\hline & 4) The time frame of small group session after the disaster \\
\hline & 5) Main contents of each session program \\
\hline & 6) Students' responses in small group sessions \\
\hline & 7) Effectiveness of small group session \\
\hline & 8) Supplementary points and additions to small group session \\
\hline \multirow[t]{5}{*}{ VII. Individual interview with teachers } & 1) Number of interviewed teachers \\
\hline & 2) Average interview time per session \\
\hline & 3) Total interview time each visit \\
\hline & 4) The time frame of individual interviews for teachers after the disaster \\
\hline & 5) Total number of sessions per teacher \\
\hline \multirow[t]{2}{*}{ VIII. Satisfaction with Participation in Volunteering } & 1) Increased capacity at the disaster site as a volunteer \\
\hline & 2) Beneficial outcomes from volunteering \\
\hline \multirow[t]{4}{*}{ IX. Thinking about future participation in volunteering } & 1) Willingness to participate as a disaster volunteer in the future \\
\hline & 2) Motivation for disaster volunteering as a consequence of 4.16 \\
\hline & 3) Need for training as a volunteer \\
\hline & 4) Comments and other opinions and suggestions \\
\hline
\end{tabular}


(15.27\%) had a bachelor's degree.

Regarding where the volunteers worked, they worked in a department of psychiatry at a university hospital ( $n=33,45.8 \%)$, a private clinic $(n=32,44.4 \%)$, or a psychiatric hospital $(n=7$, 9.7\%). Additionally, 58 (80.6\%) volunteers specialized in pediatric psychiatry. Regarding the working geographical area of the psychiatrists at the time of volunteering, they were from metropolitan areas such as Seoul, Gyeonggi and Incheon $(n=62$, $86.1 \%)$, two (2.8\%) each from Gangwon, Chungnam, Gyeongbuk, and Jeju, one (1.4\%) each from Jeonnam and Gyeongnam. The average career length of the psychiatrists was 10.97 years, with the longest career being 34 years (Table 2).

\section{Motivation of the volunteer}

The respondents learned of the opportunity to participate as a volunteer after the disaster through 'the official announcement of the Korean Neuropsychiatric Association and Korean Academy of Child and Adolescent Psychiatry' ( $n=48,63.2 \%)$. Additional responses were 'social network services (SNS)' $(\mathrm{n}=13,17.1 \%)$, 'introduction through acquaintances' $(\mathrm{n}=8$, $10.5 \%)$, 'through relevant departments of hospitals' ( $n=2,2.6 \%)$, 'media' ( $n=2,2.6 \%)$, and 'website' $(n=2,2.6 \%)$. In addition, 3 psychiatrists $(3.9 \%)$ participated through a relationship with the government. Multiple responses were acknowledged as answers to this question.

Regarding the motives for applying to be a volunteer, the responses were 'to help children and adolescents who experienced the disaster' ( $n=69,56.1 \%)$, 'to experience disaster situations and acquire relevant knowledge' ( $n=18,14.6 \%)$, and 'for self-realization through volunteerism' ( $n=4,3.3 \%)$. In ad- dition, other individual opinions were 'to assist and supervise the activities of volunteer professionals', 'because volunteers are responsible pediatric psychiatrists', 'working for the department in charge', and 'to be involved without reason'. On the other hand, only $8(11.11 \%)$ out of the total respondents reported that they had participated as a volunteer at a previous domestic disaster.

\section{Period of volunteering}

The average time spent by the volunteer psychiatrists to travel from their residence to the volunteer site was 1.76 hours ( \pm 0.98 ; range: 30 minutes to 6 hours). Additionally, the average travel time from their workplace to the volunteer site was 1.81 hours ( \pm 1.07 ; range: 18 minutes to 6 hours). On average, the number of visits to the disaster site was $8.83( \pm 11.00)$, ranging from one $(n=6)$ to $60(n=2)$. The first volunteer start date was April 16, and the last volunteer end date was November 30, which was a total of 229 days. There were two psychiatrists who volunteered from the day of the disaster, and 36 (50\%) had volunteered by April 20, the fifth day of the disaster. Total cumulative volunteer days were 4107 days, with an average of 57.04 days (range: 1 to 197 days) (Table 3).

\section{Training as a volunteer}

Shortly after the disaster, basic training of the intervention was provided to the volunteer psychiatrists. However, since the volunteers participated in the training according to their working hours and circumstances, the dates and times of their training were not unified. As a result, 61 (84.7\%) of 72 respondents reported that they received basic education. The con-

Table 2. Demographic characteristics of the study subjects $(N=72)$

\begin{tabular}{|c|c|c|c|}
\hline Variables & Male $(\mathrm{N}=21), \mathrm{N}(\%)$ & Female $(\mathrm{N}=51), \mathrm{N}(\%)$ & Total $(\mathrm{N}=72), \mathrm{N}(\%)$ \\
\hline Age, mean (SD) & $46.14(8.49)$ & $42.65(8.01)$ & $43.67(8.25)$ \\
\hline \multicolumn{4}{|l|}{ Education } \\
\hline Ph.D. & $8(38.1)$ & $28(54.9)$ & $36(50.0)$ \\
\hline Master's degree & $9(42.8)$ & $16(31.3)$ & $25(34.7)$ \\
\hline Bachelor's degree & $4(19.1)$ & $7(13.7)$ & $11(15.27)$ \\
\hline \multicolumn{4}{|l|}{ Institution type } \\
\hline University hospital & $4(19.0)$ & $29(56.86)$ & $33(45.8)$ \\
\hline Private clinic & $14(66.7)$ & $18(35.30)$ & $32(44.4)$ \\
\hline Psychiatric hospital & $3(14.3)$ & $4(7.8)$ & $7(9.7)$ \\
\hline \multicolumn{4}{|l|}{ Working geographical locations } \\
\hline Urban & $17(81.0)$ & $45(88.2)$ & $62(86.1)$ \\
\hline Rural & $4(19.0)$ & $6(11.8)$ & $10(13.9)$ \\
\hline \multicolumn{4}{|l|}{ Career as a psychiatrist (years) } \\
\hline$<10$ & $5(23.8)$ & $22(43.1)$ & $27(37.5)$ \\
\hline 10 or more & $16(76.2)$ & $29(56.9)$ & $45(62.5)$ \\
\hline
\end{tabular}

SD: standard deviation 
Table 3. Total duration of volunteer work $(\mathrm{N}=72)$

\begin{tabular}{|c|c|c|c|c|c|c|c|}
\hline Variables & $\begin{array}{c}\text { Male } \\
(\mathrm{N}=21), \\
\mathrm{N}(\%)\end{array}$ & $\begin{array}{c}\text { Female } \\
(\mathrm{N}=51), \\
\mathrm{N}(\%)\end{array}$ & $\begin{array}{c}\text { University } \\
\text { Hospital } \\
(\mathrm{N}=33), \mathrm{N}(\%)\end{array}$ & $\begin{array}{c}\text { Others } \\
(\mathrm{N}=39), \\
\mathrm{N}(\%)\end{array}$ & $\begin{array}{c}\text { Career }>10 \\
(\mathrm{~N}=45), \\
\mathrm{N}(\%)\end{array}$ & $\begin{array}{c}\text { Career }<10 \\
(\mathrm{~N}=27), \\
\mathrm{N}(\%)\end{array}$ & $\begin{array}{c}\text { Total } \\
(\mathrm{N}=72), \\
\mathrm{N}(\%)\end{array}$ \\
\hline$<1 \mathrm{wk}$ & $7(33.4)$ & $10(19.7)$ & $10(30.3)$ & $7(18.0)$ & $9(20.0)$ & $8(29.7)$ & $17(23.6)$ \\
\hline $1-2 \mathrm{wk}$ & $0(0.00)$ & $7(13.7)$ & $6(18.2)$ & $1(2.6)$ & $4(8.9)$ & $3(11.1)$ & $7(9.7)$ \\
\hline $3-4 \mathrm{wk}$ & $3(14.3)$ & $8(15.7)$ & $5(15.1)$ & $6(15.3)$ & $7(15.6)$ & $4(14.8)$ & $11(15.3)$ \\
\hline $1-2 \mathrm{~m}$ & $4(19.0)$ & $6(11.7)$ & $3(9.1)$ & $7(18.0)$ & $7(15.6)$ & $3(11.1)$ & $10(13.9)$ \\
\hline $2-3 \mathrm{~m}$ & $3(14.3)$ & $8(15.7)$ & $3(9.1)$ & $8(20.5)$ & $6(13.3)$ & $5(18.5)$ & $11(15.3)$ \\
\hline$>3 \mathrm{~m}$ & $4(19.0)$ & $12(23.5)$ & $6(18.2)$ & $10(25.6)$ & $12(26.6)$ & $4(14.8)$ & $16(22.2)$ \\
\hline
\end{tabular}

University Hospital: working in a department of psychiatry or university hospital, Others: working at a private clinic or psychiatric hospital, Career $>10$ : career as a psychiatrist over 10 years, Career $<10$ : career as a psychiatrist under 10 years

tents of the training program were as follows: orientation (introduction of the disaster site, assignment of volunteers) ( $\mathrm{n}=54$, $36.5 \%$ ), basic education (role, task, and attitude of the volunteers) $(\mathrm{n}=34,23.0 \%)$, practical training (psychological intervention and programs) $(\mathrm{n}=41,27.7 \%)$, retraining (improvement in quality of the professional and relieve psychological exhaustion) ( $\mathrm{n}=10,6.8 \%)$, and supervision $(\mathrm{n}=9,6.1 \%)$. Overall, the volunteer psychiatrists participated in the training program for less than 2 hours ( $\mathrm{n}=19,26.4 \%), 2$ hours to less than 5 hours ( $\mathrm{n}=25,34.7 \%), 5$ hours to less than 10 hours ( $\mathrm{n}=8$, $11.1 \%)$, or more than 10 hours ( $\mathrm{n}=9,12.5 \%$ ) (Table 4 ).

\section{Activities of the volunteers}

During the period of volunteering, 33 (45.83\%) of the volunteers participated in the meetings with organizers. Fortytwo $(58.33 \%)$ discussed with specialists the intervention for the students, and 41 (56.94\%) patrolled the school. There were $52(72.22 \%)$ volunteers who interviewed the students individually, 27 (37.50\%) who interacted with students in group sessions, and 15 (20.83\%) who conducted small group sessions in the counseling room in the school or hospital. Additionally, $16(22.22 \%)$ of the respondents reported that they interviewed the teachers. On the other hand, the cumulative total time spent waiting for interviews in the school was 392 hours, which means that they waited an average of 8.90 hours per person. The activities of volunteer psychiatrists while they were waiting for the counseling sessions were as follows: sharing information with the students, understanding the disaster site, communicating with other practitioners or volunteers, writing reports and interviews, discussing information related to crisis intervention among specialists, preparing for an interview with a student, reading books related to counseling, helping with administrative tasks, guidance counseling, checking announcements on the Internet and SNS, reviewing data on disaster interventions, discussing classroom situations and teachers' responses, participating in volunteer training, sharing various counseling experiences and cases, learning the guidelines of counseling, organizing the questionnaires and instructions for parents, and building a program for psychological intervention (Table 4).

\section{Individual interviews with students}

A total of 52 volunteer psychiatrists interviewed 227 students. We excluded 15 cases with unclear information and analyzed the results of interviews conducted with 212 students. The average number of students interviewed by each psychiatrist was 4.37. In the case of a specialist who interviewed the most students, he consulted a total of 10 students. The time frame for the interviews ranged from the first two weeks after the accident ( $\mathrm{n}=87,38.3 \%), 2$ weeks to 4 weeks $(\mathrm{n}=84,37.0 \%)$, and from 4 weeks to 6 months ( $\mathrm{n}=56,24.7 \%$ ). The average duration of each interview session was $40-50$ minutes ( $\mathrm{n}=25,34.7 \%$ ), followed by less than 20 minutes ( $\mathrm{n}=20,27.8 \%), 30-40 \mathrm{~min}$ utes ( $\mathrm{n}=15,20.8 \%)$, and $20-30$ minutes ( $\mathrm{n}=11,15.3 \%)$. The average time engaged in interviews in a day was less than 2 hours $(\mathrm{n}=29,40.3 \%), 2-3$ hours $(\mathrm{n}=17,23.6 \%), 3-4$ hours $(\mathrm{n}=5,6.9 \%)$, and $4-5$ hours $(\mathrm{n}=1,1.4 \%)$. The average number of interviews per student was 1.96 sessions, with a minimum of one session and a maximum of six sessions.

\section{Characteristics of the individual interviews with students}

There were 23 times (5.53\%) when the students were not interviewed due to missing the scheduled interview time. Regarding the individual interviews, the level of receptivity of the students to being interviewed was divided into a high level $(\mathrm{n}=135,63.7 \%)$, a middle level $(\mathrm{n}=68,32.1 \%)$, and a low level ( $\mathrm{n}=9,4.2 \%)$. In addition, the degree of positive change in the students after the interview was high $(\mathrm{n}=49,18.9 \%)$, medium ( $\mathrm{n}=147,69.3 \%)$, and low $(\mathrm{n}=25,11.8 \%)$. Regarding activity after the interview, 94 students (43\%) were able to terminate their counseling, while others received recommendations for continued counseling ( $\mathrm{n}=82,38.7 \%)$, medical treatment $(n=23,10.8 \%)$, family therapy $(n=6,2.8 \%)$, psy- 
Table 4. Training education of the volunteers $(\mathrm{N}=72)$

\begin{tabular}{|c|c|c|c|c|c|c|c|}
\hline Variables & $\begin{array}{c}\text { Male } \\
(\mathrm{N}=21), \\
\mathrm{N}(\%)\end{array}$ & $\begin{array}{c}\text { Female } \\
(\mathrm{N}=51), \\
\mathrm{N}(\%)\end{array}$ & $\begin{array}{c}\text { University } \\
\text { Hospital } \\
(\mathrm{N}=33), \mathrm{N}(\%)\end{array}$ & $\begin{array}{c}\text { Others } \\
(\mathrm{N}=39), \\
\mathrm{N}(\%)\end{array}$ & $\begin{array}{c}\text { Career }>10 \\
(\mathrm{~N}=45), \\
\mathrm{N}(\%)\end{array}$ & $\begin{array}{c}\text { Career }<10 \\
(\mathrm{~N}=27), \\
\mathrm{N}(\%)\end{array}$ & $\begin{array}{c}\text { Total } \\
(\mathrm{N}=72), \\
\mathrm{N}(\%)\end{array}$ \\
\hline \multicolumn{8}{|l|}{ Completion of basic training program } \\
\hline Yes & $19(90.5)$ & $42(82.4)$ & $26(78.8)$ & $35(89.7)$ & $37(82.2)$ & $24(88.9)$ & $61(84.7)$ \\
\hline No & $2(9.5)$ & $9(17.6)$ & $7(21.2)$ & $4(10.3)$ & $8(17.8)$ & $3(11.1)$ & $11(15.3)$ \\
\hline \multicolumn{8}{|l|}{ Details of the training program* } \\
\hline Orientation & $19(90.5)$ & $35(68.6)$ & $23(69.7)$ & $31(79.5)$ & $32(71.1)$ & $22(81.5)$ & $54(36.5)$ \\
\hline Basic theory education & $12(57.1)$ & $22(43.1)$ & $10(30.3)$ & $24(61.5)$ & $20(44.4)$ & $14(51.9)$ & $34(23.0)$ \\
\hline Practical training & $11(52.4)$ & $30(58.8)$ & $18(54.5)$ & $23(59.0)$ & $28(62.2)$ & $13(48.1)$ & $41(27.7)$ \\
\hline Booster session & $1(4.8)$ & $9(17.6)$ & $6(18.2)$ & $4(10.3)$ & $7(15.6)$ & $3(11.1)$ & $10(6.8)$ \\
\hline Supervision & $2(9.5)$ & $7(13.7)$ & $3(9.1)$ & $6(15.4)$ & $5(11.1)$ & $4(14.8)$ & $9(6.1)$ \\
\hline \multicolumn{8}{|c|}{ Total time of education for volunteers (h) } \\
\hline 0 & $2(9.5)$ & $9(17.6)$ & $8(24.2)$ & $3(7.7)$ & $6(13.3)$ & $3(11.1)$ & $11(15.3)$ \\
\hline$<2 \mathrm{~h}$ & $5(23.8)$ & $14(27.4)$ & $11(33.3)$ & $8(20.5)$ & $9(20.0)$ & $10(37.0)$ & $19(26.4)$ \\
\hline $2-5 \mathrm{~h}$ & $9(42.9)$ & $16(31.4)$ & $8(24.2)$ & $17(43.6)$ & $15(33.3)$ & $10(37.0)$ & $25(34.7)$ \\
\hline $5-10 \mathrm{~h}$ & $2(9.5)$ & $6(11.8)$ & $5(15.2)$ & $3(7.7)$ & $8(17.8)$ & $1(3.8)$ & $8(11.1)$ \\
\hline$>10 \mathrm{~h}$ & $3(14.3)$ & $6(11.8)$ & $1(3.1)$ & $8(20.5)$ & $7(15.6)$ & $3(11.1)$ & $9(12.5)$ \\
\hline \multicolumn{8}{|l|}{ Activities of volunteers* } \\
\hline $\begin{array}{l}\text { Attending a meeting of } \\
\text { practitioners }\end{array}$ & $8(38.1)$ & $25(49.0)$ & $15(45.5)$ & $18(46.2)$ & $23(51.1)$ & $10(37.0)$ & $33(45.8)$ \\
\hline $\begin{array}{l}\text { Discussions on intervention } \\
\text { between specialists }\end{array}$ & $13(61.9)$ & $29(56.9)$ & $17(51.5)$ & $25(64.1)$ & $30(66.7)$ & $12(44.4)$ & $42(58.3)$ \\
\hline Patrol in school & $10(47.6)$ & $31(60.8)$ & $20(60.6)$ & $21(53.8)$ & $24(53.3)$ & $17(63.0)$ & $41(56.9)$ \\
\hline $\begin{array}{l}\text { Individual interview with } \\
\text { students }\end{array}$ & $15(71.4)$ & $37(72.5)$ & $23(69.7)$ & $29(74.4)$ & $31(68.9)$ & $21(77.8)$ & $52(72.2)$ \\
\hline $\begin{array}{l}\text { Participation in a group session } \\
\text { (classroom) }\end{array}$ & $11(52.4)$ & $16(31.4)$ & $6(18.2)$ & $21(53.8)$ & $20(44.4)$ & $7(25.9)$ & $27(37.5)$ \\
\hline $\begin{array}{l}\text { Participation in a small group } \\
\text { session }\end{array}$ & $3(14.3)$ & $12(23.5)$ & $7(21.2)$ & $8(20.5)$ & $10(22.2)$ & $6(22.2)$ & $15(20.8)$ \\
\hline $\begin{array}{l}\text { Individual interview with } \\
\text { teachers }\end{array}$ & $2(9.5)$ & $14(27.4)$ & $5(15.2)$ & $11(28.2)$ & $12(26.7)$ & $4(14.8)$ & $16(22.2)$ \\
\hline
\end{tabular}

University Hospital: working in a department of psychiatry or university hospital; Others: working at a private clinic or psychiatric hospital. Career $>10$ : career as a psychiatrist over 10 years, Career $<10$ : career as a psychiatrist under 10 years. *multiple response items; grade response percentages are based on a total sample

chotherapy and medical treatment together $(\mathrm{n}=5,2.4 \%)$, and medical treatment and family therapy together $(n=2,0.9 \%)$.

\section{Participation in group sessions}

Twenty-seven (38.6\%) volunteer psychiatrists reported that they had conducted group sessions in the classroom more than once. The time period for these interventions was as follows: hyperacute phase (immediately after the accident -2 weeks) $(n=18,66.7 \%)$, acute phase $(2-4$ weeks $)(n=8,29.6 \%)$, and subacute phase (1-6 months) ( $n=1,3.7 \%)$. The number of sessions for a particular group was 1 session $(n=20,74.1 \%)$, 2 sessions $(n=5,18.5 \%), 3$ sessions $(n=1,3.7 \%)$, and 5 ses- sions $(\mathrm{n}=1,3.7 \%)$.

The content of the group program included psychoeducation, definition of trauma, the acute stress response, types of stress, exercises expressing emotions and thoughts, understanding the processes of loss and mourning, stabilization, coping with the media, writing letters to friends, adapting to school, and breathing and muscle relaxation exercises. From the viewpoint of the psychiatrists and as a result of observing the responses of the students who participated in the group program, the students responded at a high level $(n=3,11.1 \%)$, an intermediate level $(n=19,70.4 \%)$ and a low level $(n=5,18.5 \%)$. For the question of whether the group sessions were effective, 
almost $60 \%$ of the psychiatrists answered positively ('agree' $(n=13,48.1 \%)$ and 'strongly agree' $(n=3,11.1 \%))$. Other answers were 'neutral' ( $n=6,22.2 \%)$ and 'disagree' $(n=5,18.5 \%)$.

\section{Participation in small group sessions}

We analyzed the experiences of 15 volunteer psychiatrists who had consulted for students in small groups; six of them (40.0\%) had consultations in the counseling room at the school, and nine (60.0\%) were at the Ansan Korea hospital. Of these, 6 psychiatrists participated in one session, 7 psychiatrists conducted two sessions, and 2 psychiatrists were involved in four sessions. Regarding the time frame of the small group sessions, the majority of them, 11 (73.3\%), were in the hyperacute phase (immediately after the accident-2 weeks). Other sessions occurred during the acute phase ( $2-4$ weeks) $(n=3,20.0 \%)$ or the subacute phase ( 1 month to 6 months) ( $n=3,6.7 \%)$.

The contents of the small group sessions included offering support for mourning, evaluating psychological assessments, sharing experiences and symptoms, expressing moods or feeling, handling the guilt felt for the victims, suggesting alternative thinking methods, and teaching recovery techniques (TRT). Examination of the level of the students' attitudes in the small groups, only $2(13.3 \%)$ psychiatrists reported that the responses of the students were at a high level, the majority of psychiatrists, 10 (66.7\%), reported an intermediate level, and $3(20.0 \%)$ psychiatrists reported a low level of interest. These data were contrary to the results of the individual interviews.

\section{Individual interviews with the teachers}

Sixteen volunteer psychiatrists individually interviewed 32 teachers in the school. The psychiatrists who interviewed the most teachers consulted four teachers each. These interventions occurred most frequently during the hyperacute phase (immediately after the accident -2 weeks) $(n=21,65.6 \%)$, followed by the acute phase $(2-4$ weeks) $(n=5,15.6 \%)$ and the subacute phase (1-6 months) $(n=2,6.3 \%)$. Teachers were interviewed during 1 session $(n=23,71.9 \%), 2$ sessions $(n=5$, $15.6 \%), 3$ sessions $(n=2,6.3 \%), 5$ sessions $(n=1,3.1 \%)$, and 6 sessions $(n=1,3.1 \%)$. The duration of these interview sessions was $40-50$ minutes $(n=6,37.5 \%)$, more than 50 minutes $(n=4$, $25.0 \%), 30-40$ minutes $(n=3,18.8 \%)$ and $20-30$ minutes $(n=3$, $18.8 \%)$. The average total time spent interviewing teachers per day for each visit to the school was less than 2 hours $(n=14,87.5 \%)$ or $2-3$ hours $(n=2,12.5 \%)$.

\section{Satisfaction with volunteering}

More than three-quarters of the total responding psychiatrists answered positively about participating in volunteer activities after the Sewol Ferry disaster ['strongly agree' ( $n=12$, $16.6 \%)$ and 'agree' $(n=43,59.7 \%)]$. The responses about satis- faction with volunteering are categorized by content and presented in Table 5.

\section{Willingness to participate as a volunteer in the future}

In the event of a disaster in the future, all but five of the respondents answered positively that they were willing to volunteer as a psychiatrist again ['strongly agree' $(n=19,26.3 \%)$ and 'agree' ( $n=48,66.7 \%)]$. More than $80 \%$ of respondents answered positively about whether the volunteer activities following the Sewol Ferry disaster were an opportunity to set an intention of future volunteering ['strongly agree' $(n=23$, $32.4 \%)$, 'agree' $(n=36,50.0 \%)]$.

The respondents provided opinions on the training and additional requirements that need to be considered when implementing volunteering after a disaster: training of psychological first aid (PFA) (mourning reactions and notifying others of the death of teachers and peers) $(n=54,24.5 \%)$, training in identifying precise roles in a disaster situation $(n=43,19.5 \%)$, building an education system for professionals ( $n=37,16.8 \%)$, training systematic evaluation and treatment by age and symptom $(n=29,13.2 \%)$, coordinating communication between leader and coleader in group sessions $(n=28,12.7 \%)$, and understanding precautions relevant to interviewing individuals, groups, and teachers ( $\mathrm{n}=28,12.7 \%)$. In addition, we categorized additional opinions based on the contents regarding training issues to be considered when volunteering, and the analysis results are presented (Figures 1 and 2).

\section{DISCUSSION}

After the 9/11 attacks, volunteer psychiatrists provided services including brief counseling encounters, medication, referrals for ongoing care, and psychiatric assessment. ${ }^{2}$ It could represent the need of the psychiatrist's tasks in a nonmedical setting. Collecting and analyzing the information about disaster-related experiences could predict psychological problems of survivors exposed to traumatic events. ${ }^{1}$ International mental health guidelines have also recommended that the medical needs of affected areas be identified, and psychological support should be provided through connections with community organizations. ${ }^{4}$

Especially in the predisaster phase, it is necessary to prepare a plan for communicating in the community and provide advance education among the specialists about mental health concerns during a disaster. Children and adolescents experiencing trauma in disasters generally respond differently than adults, therefore volunteers need to be educated in advance. ${ }^{8,9}$ Furthermore, volunteers should be given a specific role accompanied by training in the field for crisis intervention. Using these principles, PFA is usually supported in acute 
Table 5. Satisfaction with participation in volunteering $(\mathrm{N}=72)$

\begin{tabular}{|c|c|c|c|c|c|c|c|}
\hline Variables & $\begin{array}{c}\text { Male } \\
(\mathrm{N}=21), \\
\mathrm{N}(\%)\end{array}$ & $\begin{array}{c}\text { Female } \\
(\mathrm{N}=51), \\
\mathrm{N}(\%)\end{array}$ & $\begin{array}{c}\text { University } \\
\text { Hospital } \\
(\mathrm{N}=33), \mathrm{N}(\%)\end{array}$ & $\begin{array}{c}\text { Others } \\
(\mathrm{N}=39), \\
\mathrm{N}(\%)\end{array}$ & $\begin{array}{c}\text { Career }>10 \\
(\mathrm{~N}=45), \\
\mathrm{N}(\%)\end{array}$ & $\begin{array}{c}\text { Career }<10 \\
(\mathrm{~N}=27), \\
\mathrm{N}(\%)\end{array}$ & $\begin{array}{c}\text { Total } \\
(\mathrm{N}=72), \\
\mathrm{N}(\%)\end{array}$ \\
\hline \multicolumn{8}{|c|}{ Increased capacity at the disaster site as a volunteer } \\
\hline Strongly disagree & $0(0.0)$ & $0(0.0)$ & $0(0.0)$ & $0(0.0)$ & $0(0.0)$ & $0(0.0)$ & $0(0.0)$ \\
\hline Disagree & $0(0.0)$ & $3(5.9)$ & $0(0.0)$ & $3(7.7)$ & $2(4.4)$ & $1(3.7)$ & $3(4.2)$ \\
\hline Neutral & $6(28.6)$ & $8(15.7)$ & $7(21.2)$ & $7(17.9)$ & $8(17.8)$ & $6(22.2)$ & $14(19.4)$ \\
\hline Agree & $9(42.8)$ & $34(66.7)$ & $22(66.7)$ & $21(53.9)$ & $27(60.0)$ & $16(59.3)$ & $43(59.7)$ \\
\hline Strongly agree & $6(28.6)$ & $6(11.7)$ & $4(12.1)$ & $8(20.5)$ & $8(17.8)$ & $4(14.8)$ & $12(16.6)$ \\
\hline \multicolumn{8}{|c|}{ Motivation for disaster volunteering as a consequence of 4.16} \\
\hline Strongly disagree & $0(0.0)$ & $1(1.9)$ & $0(0.0)$ & $1(2.6)$ & $0(0.0)$ & $1(3.7)$ & $1(1.4)$ \\
\hline Disagree & $1(4.8)$ & $2(3.9)$ & $2(6.0)$ & $1(2.6)$ & $1(2.2)$ & $2(7.4)$ & $3(4.2)$ \\
\hline Neutral & $2(9.5)$ & $6(11.7)$ & $3(9.1)$ & $5(12.8)$ & $5(11.1)$ & $3(11.1)$ & $8(11.1)$ \\
\hline Agree & $12(57.1)$ & $25(49.1)$ & $19(57.6)$ & $18(46.1)$ & $24(53.4)$ & $13(48.1)$ & $37(50.9)$ \\
\hline Strongly agree & $6(28.6)$ & $17(33.4)$ & $9(27.3)$ & $14(35.9)$ & $15(33.3)$ & $8(29.7)$ & $23(32.4)$ \\
\hline \multicolumn{8}{|c|}{ Willingness to participate as a disaster volunteer in the future } \\
\hline Strongly disagree & $0(0.0)$ & $0(0.0)$ & $0(0.0)$ & $0(0.0)$ & $0(0.0)$ & $0(0.0)$ & $0(0.0)$ \\
\hline Disagree & $0(0.0)$ & $1(1.9)$ & $0(0.0)$ & $1(2.6)$ & $1(2.2)$ & $0(0.0)$ & $1(1.4)$ \\
\hline Neutral & $2(9.5)$ & $2(3.9)$ & $1(3.0)$ & $3(7.7)$ & $3(6.7)$ & $1(3.7)$ & $4(5.6)$ \\
\hline Agree & $14(66.7)$ & $34(66.7)$ & $23(69.7)$ & $25(64.1)$ & $29(64.4)$ & $19(70.4)$ & $48(66.7)$ \\
\hline Strongly agree & $5(23.8)$ & $14(27.5)$ & $9(27.3)$ & $10(25.6)$ & $12(26.7)$ & $7(25.9)$ & $19(26.3)$ \\
\hline
\end{tabular}

University Hospital: working in a department of psychiatry or university hospital; Others: working at a private clinic or psychiatric hospital. Career $>10$ : career as a psychiatrist over 10 years, Career $<10$ : career as a psychiatrist under 10 years

phase after a disaster. ${ }^{8,10}$ In the United States, the New York Mental Health Department and the Red Cross have teamed up with Disaster Psychiatry Outreach (DPO) in 1998 to quickly respond to crisis situations in the community. ${ }^{2}$ In Japan, in April 2013, the Disaster Psychiatric Assistance Team (DPAT) was created and is composed of mental health experts such as psychiatrists, nurses, pharmacists, mental health social workers and clinical psychologists. DPAT provides mental health care support in large disaster-affected areas. ${ }^{4}$

Since the September 11, 2001 terrorist attacks in the United States, the DPO has provided counseling for over 2,000 victims through 268 volunteer psychiatrists over a two-month period. They provided guidance to 848 patients on psychiatric evaluations, medications, and recommendations for continued treatment. ${ }^{2}$ In addition, if a disaster occurs in Japan, the DPAT headquarters would be established within 48 hours in the psychiatric hospital, public health center, and shelters in the affected area. They cooperate closely with health workers and conduct medical consultation activities together. In general, the standard is a one-week period of activity, and various reports on DPAT activities have been recorded in the Disaster Mental Health Information Support System (DMHISS). ${ }^{4}$

In South Korea, however, there is a lack of systematic con- struction of such a structure of specialists related to disaster. Nevertheless, after the Sewol Ferry disaster, specialists from various fields collaborated to conduct psychosocial interventions for the victims who experienced the disaster.

In Danwon High School, special volunteers conducted group sessions and interviewed students and teachers individually. The volunteer psychiatrists also provided psychological counseling to students who experienced indirect posttraumatic stress in areas other than Danwon High School. Volunteers after a disaster served to provide the psychosocial support in the midst of crisis and confusion. ${ }^{11}$ It has been reported that through volunteer experience, these volunteers felt internal growth on an individual level and were motivated by social relationships, positive change and enhanced meaning of life. ${ }^{12}$ It was learned from this study that the volunteer psychiatrists were able to form a close bond between professional workers in the disaster area after the Sewol Ferry disaster. Additionally, they mentioned positive aspects including the significance of participation, self-esteem as a clinician, and the experience of value recognition.

However, a previous study has reported that volunteers after a disaster had a risk of developing posttraumatic stress disorder (PTSD) that ranged from $24 \%$ to $46 \% .{ }^{13}$ Volunteers should implement appropriate self-management strategies 


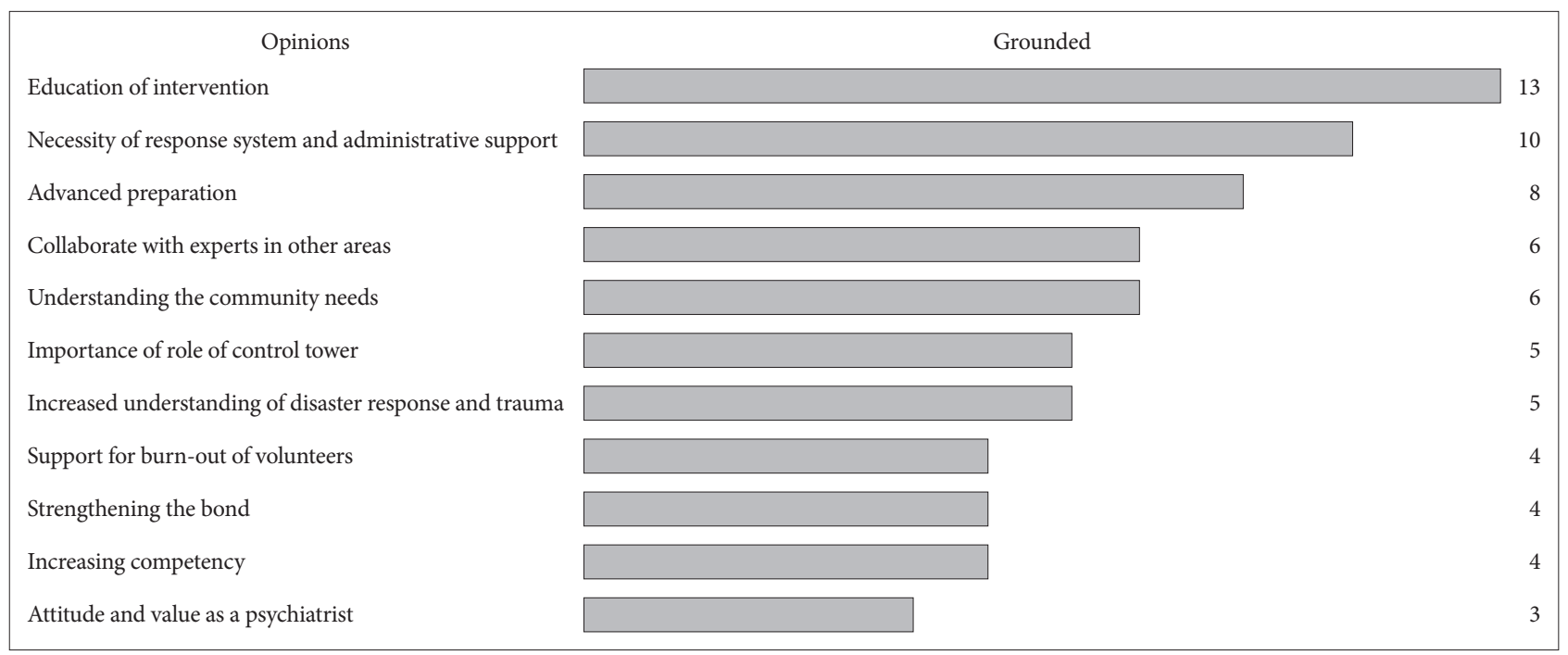

Figure 1. Qualitative data analysis of the opinions and suggestions from volunteer psychiatrists.

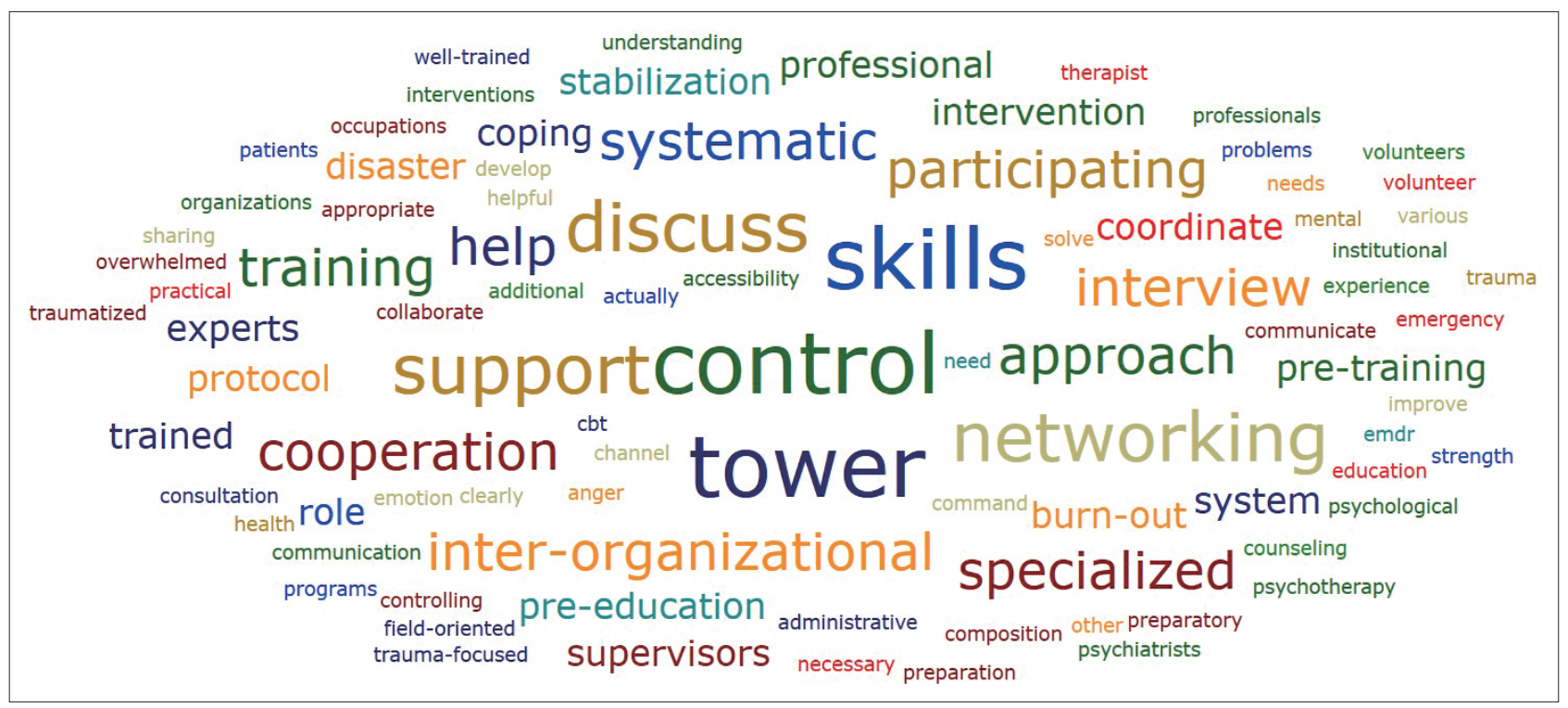

Figure 2. Word cloud of the qualitative data analysis of the opinions from volunteer psychiatrists.

during volunteer and relief activities at disaster sites.

It is important to note that when self-management is lacking, volunteers have a variety of experiences in crisis situations, which can increase negative psychological reactions and reduce self-efficacy. ${ }^{14}$ A survey of 506 volunteers who worked at the time of the earthquake in Indonesia found a high level of PTSD symptoms even after a year and six months after the disaster. ${ }^{15}$ In addition, a previous study proved that exposure to specific tasks had a negative effect on volunteers, with symptoms such as PTSD, depression, and anxiety. ${ }^{16}$ In a previous study ${ }^{17}$ of adult volunteers in the Jindo area in Korea, 151 community volunteers (19.7\%) showed symptoms of PTSD, which suggested the need for mental health services. Therefore, psychological support for disaster volunteers is needed and a plan should be prepared for their burn-out. ${ }^{3}$

The abovementioned DPO in the United States provides specialists in the fields of medical, public health and emergency management education and training on disaster mental health and maintains a database of the latest academic information. ${ }^{18}$ The DPO are trained on a regular basis and, if disasters occur, are briefly trained and then intervene. Similarly, DPAT in Japan conducts nationwide training in preparation for a disaster response. They recommend specialists attend training education for DPAT to improve their effectiveness. ${ }^{19}$ In Korea, it is necessary to have a systematic intervention system in order to improve the participation rate of mental health professionals as volunteers in the future, and measures for avoiding or dealing with exhaustion of volunteers should 
be devised. ${ }^{15}$

Likewise, just as the role of experts in disaster interventions should be defined, the training of psychological support personnel who provide the primary contact and PFA at the disaster site should be defined. ${ }^{20}$ In particular, the analysis of the individual opinions in this study emphasized the need for a top-down structure from the control tower to the subsystems, with a clear understanding of the role of the control tower and the command system. In this situation for example, having preparations in place for empowering the school doctor, who connected the system between psychiatrists and the school, should be established. In addition, a civilian volunteer organization composed of disaster-related mental health professionals other than the professional associations is required to strengthen the capacity through a specialized approach. ${ }^{21,22}$

In a situation of a national disaster involving children and adolescents, such as the Sewol Ferry disaster, preparations should be made in advance for the systematic training of responders to minimize the initial chaos and for the implementation of the intervention protocol for children and adolescents. It is necessary to prepare thoroughly for group programs in the classroom for the children and adolescents exposed to a disaster directly or indirectly. It is necessary to know the appropriate guidelines, such as the detailed progression of an intervention program, how to implement the procedure in a class, and the necessary precautions.

The limitations of this study are as follows. The questionnaire was only created for and used by psychiatrists in South Korea. Because we focused on volunteer experience in a particular context, Danwon High School after this disaster, we could not more generally address mental health intervention services for other areas. Furthermore, the study represents a limited investigation based on data that is reliant on volunteers' recall of their experience. Nevertheless, it is meaningful that the results of this study were derived from the experiences of psychiatrists who voluntarily participated in the response after the Sewol Ferry disaster in South Korea.

\section{Conclusions}

The purpose of this study was to investigate the mental health intervention experience corresponding to a total of $1,480.45$ hours of volunteer time accumulated by 72 psychiatrists who participated as volunteers after the Sewol Ferry disaster. The professional role of psychiatrists who were involved from the hyperacute phase of the disaster have had a positive impact on students and teachers in Danwon High School. However, we found that more systematic preparation was needed regarding the process of crisis counseling and psychosocial intervention in confusing disaster sites. The results of this study are expected to help prepare for appropriate and more effective crisis responses from the medical and psychological fields in the future. Furthermore, creation of an organic and systematic mental health intervention system from disaster control towers down through command systems to the subsystems is expected to contribute to building mental health intervention services for children and adolescents.

\section{Acknowledgments}

This study was supported by a grant of the Korea Mental Health Technology R\&D Project, Ministry of Health \& Welfare, Republic of Korea (HM15C1058).

\section{Conflicts of Interest}

The authors have no potential conflicts of interest to disclose.

\section{Author Contributions}

Conceptualization: Soo-Young Bhang, Mi-Sun Lee. Data curation: SooYoung Bhang, Mi-Sun Lee, Seung Min Bae, Eunji Kim. Formal analysis: Mi-Sun Lee, Soo-Young Bhang, Seung Min Bae. Funding acquisition: SooYoung Bhang, Mi-Sun Lee. Investigation: Soo-Young Bhang. Methodology: Juhyun Lee, Jiyoun Kim, Eunji Kim. Project administration: Soo-Young Bhang, Jun-Won Hwang, Mi-Sun Lee. Resources: Seung Min Bae, CheolSoon Lee, Jangho Park, Eunji Kim. Software: Cheol-Soon Lee, Jangho Park. Supervision: Jun-Won Hwang, Soo-Young Bhang. Validation: MiSun Lee, Soo-Young Bhang, Hyoung Yoon Chang. Visualization: Mi-Sun Lee, Hyoung Yoon Chang. Writing-original draft: Mi-Sun Lee, Seung Min Bae, Soo-Young Bhang. Writing-review \& editing: Seung Min Bae, Mi-Sun Lee, Soo-Young Bhang.

\section{ORCID iDs}

Soo-Young Bhang http://orcid.org/0000-0001-5254-0314

Seung Min Bae http://orcid.org/0000-0003-3732-6824

Mi-Sun Lee http://orcid.org/0000-0003-2918-0546

\section{REFERENCES}

1. van den Berg B, Wong A, van der Velden PG, Boshuizen HC, Grievink L. Disaster exposure as a risk factor for mental health problems, eighteen months, four and ten years post-disaster--a longitudinal study. BMC Psychiatry 2012;12:147.

2. Pandya A, Katz CL, Smith R, Ng AT, Tafoya M, Holmes A, et al. Services provided by volunteer psychiatrists after $9 / 11$ at the New York City family assistance center: September 12-November 20, 2001. J Psychiatr Pract 2010;16:193-199.

3. Takahashi S. Mental health support for disaster relief personnel. Seishin Shinkeigaku Zasshi 2014;116:224-230.

4. DPAT (Disaster Psychiatric Assistance Team) http://www.dpat.jp/dpat. php. Accessed February 16, 2017.

5. North CS, King RV, Fowler RL, Polatin P, Smith RP, LaGrone HA, et al. Psychiatric disorders among transported hurricane evacuees: Acutephase findings in a large receiving shelter site. Psychiatr Ann 2008;38: 104-113.

6. Woo H, Cho Y, Shim E, Lee K, Song G. Public trauma after the Sewol Ferry Disaster: the role of social media in understanding the public mood. Int J Environ Res Public Health 2015;12:10974-10983.

7. Sherman S, Grode G, McCoy T, Vander Veur SS, Wojtanowski A, Sandoval BA, et al. Corner stores: the perspective of urban youth. J Acad Nutr Diet 2015;115:242-248.

8. Lee CS, Seo JY, Park J, Chang HY, Bhang SY. Psychosocial intervention and practical experience in children and adolescent before and after a disaster. J Korean Neuropsychiatr Assoc 2015;54:276-281. 
9. Pfefferbaum B, Shaw JA, American Academy of C Adolescent Psychiatry Committee on Quality I. Practice parameter on disaster preparedness. J Am Acad Child Adolesc Psychiatry 2013;52:1224-1238.

10. Kar N. Psychological impact of disasters on children: review of assessment and interventions. World J Pediatr 2009;5:5-11.

11. Call JA, Pfefferbaum B, Jenuwine MJ, Flynn BW. Practical legal and ethical considerations for the provision of acute disaster mental health services. Psychiatry 2012;75:305-322.

12. Muckaden MA, Pandya SS. Motivation of volunteers to work in palliative care setting: a qualitative study. Indian J Palliat Care 2016;22: 348353.

13. Thormar SB, Sijbrandij M, Gersons BP, Van de Schoot R, Juen B, Karlsson $\mathrm{T}$, et al. PTSD symptom trajectories in disaster volunteers: the role of self-efficacy, social acknowledgement, and tasks carried out. J Trauma Stress 2016;29:17-25.

14. Quevillon RP, Gray BL, Erickson SE, Gonzalez ED, Jacobs GA. Helping the helpers: assisting staff and volunteer workers before, during, and after disaster relief operations. J Clin Psychol 2016;72:1348-1363.

15. Thormar SB, Gersons BP, Juen B, Djakababa MN, Karlsson T, Olff M. The impact of disaster work on community volunteers: The role of peri-traumatic distress, level of personal affectedness, sleep quality and resource loss, on post-traumatic stress disorder symptoms and subjective health. J Anxiety Disord 2014;28:971-977.

16. Thormar SB, Gersons BP, Juen B, Djakababa MN, Karlsson T, Olff M.
Organizational factors and mental health in community volunteers. The role of exposure, preparation, training, tasks assigned, and support. Anxiety Stress Coping 2013;26:624-642.

17. Lee JY, Kim SW, Bae KY, Kim JM, Shin IS, Yoon JS. Factors associated with posttraumatic stress disorder symptoms among community volunteers during the Sewol ferry disaster in Korea. Compr Psychiatry 2017;77:38-44.

18. Katz CL. First person: a mental health mission to post-earthquake El Salvador. Psychiatr Clin North Am 2013;36:309-319.

19. Yamashita J, Shigemura J. The Great East Japan Earthquake, tsunami, and Fukushima Daiichi nuclear power plant accident: a triple disaster affecting the mental health of the country. Psychiatr Clin North Am 2013;36:351-370.

20. Hambrick EP, Rubens SL, Vernberg EM, Jacobs AK, Kanine RM. Towards successful dissemination of psychological first aid: a study of provider training preferences. J Behav Health Serv Res 2014;41:203215.

21. King RV, Burkle FM Jr, Walsh LE, North CS. Competencies for disaster mental health. Curr Psychiatry Rep 2015;17:548.

22. Everly GS Jr, Beaton RD, Pfefferbaum B, Parker CL. On academics: training for disaster response personnel: the development of proposed core competencies in disaster mental health. Public Health Rep 2008; 123:539-542. 